\title{
Percepção dos Idosos Sobre o Processo de Envelhecimento
}

\author{
Nicácia Souza Oliveira ${ }^{1}$; Talita Sabrine de Souza ${ }^{2}$; Francisca Silva de Alencar ${ }^{3}$; Gisele Lopes Oliveira ${ }^{4}$; \\ Natália Bastos Ferreira ${ }^{5}$; Juliana Saraiva de Alencar ${ }^{6}$
}

\begin{abstract}
Resumo: O envelhecimento é definido como um processo progressivo, no qual ocorrem alterações biológicas, funcionais, psicológicas que com o passar do tempo tendem a determinar uma acentuada perda da capacidade que o indivíduo possui de se adaptar ao meio ambiente. O acelerado crescimento da população idosa é um fenômeno no mundo e, no Brasil, esse processo ocorre de forma bastante avançada. O objetivo desse estudo é conhecer a percepção dos idosos sobre o processo de envelhecimento. Trata-se de um estudo exploratório, descritivo, com abordagem qualitativa. Utilizou-se uma entrevista semi-estruturada com 10 idosos cadastrados na Estratégia Saúde da Família do bairro Paraná, no Município de Iguatu-Ce. Posteriormente, os dados foram agrupados em categorias e analisados de acordo com a Técnica de Análise de Conteúdo de Bardin, sendo solicitada a autorização dos sujeitos da pesquisa mediante o Termo de Consentimento Livre e EsclarecidoTCLE. De acordo com os resultados do estudo constatou-se que a maioria dos idosos tinha entre 70 e 80 anos, eram do sexo feminino, viúvos, residindo com filhos e netos, apresentando baixo grau de escolaridade e renda familiar de apenas um salário mínimo. Notou-se que a maior parte dos entrevistados percebe de forma positiva seu próprio processo de envelhecimento, porém reagem negativamente às modificações que ocorrem com o avançar da idade. Observou-se que os idosos atribuem sentimentos como aceitação e alegria à velhice e que a grande maioria desconhece as políticas públicas de saúde a eles destinadas. Verificou-se também que todos os idosos consideram importante a participação da família nessa fase da vida. Dessa forma conclui-se que se faz relevante que haja mais estudos voltados para a percepção dos gerontes para que se possa compreender o processo de envelhecimento em todas as suas faces.
\end{abstract}

Palavras-chave: Saúde do Idoso; Envelhecimento, Percepção.

\section{Perception of Elderly People about Aging Process}

\begin{abstract}
Aging is defined as a gradual process in which changes occur in biological, functional, psychological, with the passing of time tend to determine a marked loss of the capacity of the individual has to adapt to the environment. The rapid growth of the elderly population is a phenomenon in the world and, in Brazil, this process is quite advanced. The aim of this study is to understand the perception of the elderly on the aging process. This is an exploratory, descriptive, qualitative approach. We used a semi-structured interview with 10 seniors enrolled in the Family Health Strategy neighborhood Paraná, in the Municipality of Iguatu-Ce. Subsequently, the data were grouped into categories and analyzed according to the technique of content analysis of Bardin, being asked to consent of research subjects through the Term of Consent - TC. According to the results of the study it was found that most of the individuals were between 70 and 80 years were female, widowed, living with children and grandchildren, with low education level and family income of one minimum wage. It was noted that the majority of respondents perceived positively their own aging process, but react negatively to the changes that occur with advancing age. It was observed that the elderly attach feelings like joy

\footnotetext{
${ }^{1}$ Professora da Universidade Regional do Cariri-URCA/UDI. Email nicaciaoliveira@ hotmail.com

${ }^{2}$ Enfermeira pela Universidade Regional do Cariri-URCA/UDI. Email thalitasabrine@ hotmail.com;

${ }^{3}$ Enfermeira pela Universidade Regional do Cariri - URCA, Especialista em Saúde da Família pela Faculdade São Francisco da Paraíba FASP, Professora da Faculdade Vale do salgado - FVS. E-mail:silvia.rami@ hotmail.com

${ }^{4}$ Enfermeira. Professora da Universidade Regional do Cariri-URCA/UDI. Email: giselelopes 4@ @otmail.com

${ }^{5}$ Enfermeira. Professora da Universidade Regional do Cariri-URCA/UDI.

${ }^{6}$ Enfermeira Graduada pela Faculdade Santa Maria, Pós-graduada em Enfermagem Clínica Médico-Cirurgica pelo Centro Universitário São Camilo; e Enfermagem do Trabalho pela Faculdades Integradas de Patos (FIP). E-mail: julianaaa100@yahoo.com.br
} 
and acceptance to old age and the vast majority is unaware of the public health policies aimed at them. It was also found that all seniors consider important family participation in this phase of life. Thus it is concluded that there is significant that most studies on the perception of gerontes so you can understand the process of aging in all its faces.

Keywords: Aging Health, Aging, Perception.

\section{Introdução}

O envelhecimento é definido como um processo progressivo, no qual ocorrem alterações biológicas, funcionais, psicológicas que com o passar do tempo tendem a determinar uma acentuada perda da capacidade que o indivíduo possui de se adaptar ao meio ambiente, resultando em uma maior fragilidade aumentando a incidência de doenças que acabam por levá-lo a morte (LIMA; MURAI, 2005).

A pessoa idosa na maioria das vezes é assim definida quando completa 60 anos, independente de como ela está fisicamente ou psicologicamente. No entanto a idade e o envelhecimento possuem vários significados que vão além da quantidade de anos que se vive (SCHNEIDER; IRIGARAY, 2008).

A Organização Mundial da Saúde (OMS) define como idoso o indivíduo de 65 anos ou mais para aqueles de países desenvolvidos e 60 anos ou mais para os indivíduos de países subdesenvolvidos (MENDES et al., 2005).

Nos dias atuais, alcançar a velhice é uma realidade, mesmo nos países economicamente mais pobres. Ainda que a melhora dos aspectos relacionados a saúde observados no século XX não tenham se distribuído de forma igualitária nos diversos países e contextos, envelhecer não é mais, como antigamente, um privilégio de poucos. O acelerado crescimento da população idosa é um fenômeno no mundo e, no Brasil, esse processo ocorre de forma bastante avançada (VERAS, 2009).

Segundo o Instituto Brasileiro de Geografia e Estatística (IBGE), o Brasil já apresenta um perfil de país de idosos, pois, em menos de vinte anos boa parte da população será de pessoas idosas. Em 2005 existiam 16 milhões de indivíduos com 60 anos ou mais, a estimativa é que em 2025 esse número passará para 32 milhões, representando 15\% da população total (RIBEIRO; PIRES, 2011).

Para Ribeiro e Pires (2011), o rápido processo de envelhecimento da população brasileira está relacionado à queda da mortalidade e da fecundidade, ocorrida, simultaneamente ao aumento na expectativa de vida.

Esse aumento na expectativa de vida, ligado à redução no número de nascimentos compõe o fenômeno chamado transição demográfica, caracterizado pelo acelerado processo de envelhecimento 
http://idonline.emnuvens.com.br/id ISSN on-line: 1981-1179

da população. Mesmo sendo natural, o envelhecimento deixa o organismo suscetível a alterações que repercute nascondições de saúde e qualidade de vida do idoso (ALVARENGA et al.,2008).Simultâneo a transição demográfica, ocorre à transição epidemiológica, que tem como característica as mudanças nos padrões de doenças e mortalidade, ocorrendo uma redução da mortalidade e preponderância das doenças crônico-degenerativas (PEREIRA et al., 2009).

De acordo com Fernandes et al (2009), são justamente essas mudanças epidemiológicas que tornam necessárias ações de reorganização da atenção a saúde do idoso, pois a velhice, geralmente vem atrelada ao aumento da incidência de doenças crônicas não transmissíveis que podem resultar em incapacidades, com potencial poder de limitar a funcionalidade do idoso.

Diante de tantas mudanças decorrentes das transições demográficas e epidemiológicas, é importante lembrar que é preciso atentar não só para os aspectos quantitativos, mas também para aqueles que vão além da quantidade, como por exemplo, a qualidade de vida dessa população (CAMACHO; COELHO, 2010).

Como bem observou Torres e Sá (2008), a velhice tem sido encarada como um mal necessário do qual não há como se escapar. Dessa forma o idoso também é encarado como um mal necessário, como alguém que já viveu sua parcela de anos, trabalhou, cuidou da família, restando agora esperar pelo fim da vida. Com a evolução das pesquisas na área da saúde, e a acessibilidade das pessoas idosas aos serviços, a população chega aos 60 anos com probabilidade de viver mais e melhor do que há vinte anos atrás.

Os mesmos autores ainda mencionam que antes do que se pensa terão pessoas se aposentando aos 60 anos e iniciando uma nova fase da vida que durará mais 30 ou 40 anos. No entanto, a oferta de serviços não é igual para todos, evidenciando as desigualdades que existem nas condições de vida e saúde dos idosos brasileiros. A velhice é caracterizada por vários aspectos, e não deve ser submetida à análise sem que antes se observe os fatores socioeconômicos e culturais, pois tais aspectos vão além de mudanças físicas e fisiológicas individuais.

O idoso está em pauta no cenário brasileiro. Atualmente muitos estudos exploram o assunto, porém a grande maioria é voltada para os profissionais que lidam com a velhice ou para os cuidadores, poucos são destinados a conhecer os sentimentos daqueles que melhor vivenciam esse processo de envelhecimento, os idosos. Daí a motivação para a escolha do tema, introduzir uma vertente pouco explorada para um assunto tão vasto e importante. A velhice precisa ser compreendida em todos os seus aspectos, não somente associada a doenças como outrora.

Diante do exposto surgiram os seguintes questionamentos, de que forma o idoso percebe o seu próprio envelhecimento? Como ele reage às modificações que vão ocorrendo em sua vida com o avançar da idade? Que sentimentos eles atribuem a esse processo? Será que eles conhecem as políticas 
públicas desenvolvidas para melhorar sua qualidade de vida? Como os idosos avaliam o papel da família no cuidado para com eles?

A intenção é que estas discussões ajudem na compreensão do processo de envelhecimento, do ponto de vista da própria pessoa idosa. Para tanto, será necessário: Traçar o perfil socioeconômico e cultural do idoso participante do estudo; Conhecer a visão do idoso acerca do significado da velhice; Investigar como os idosos reagem às modificações que ocorrem com o avançar da idade; Identificar os sentimentos atribuídos pelos idosos ao processo de envelhecimento; Investigar a visão dos idosos sobre a participação familiar no processo de envelhecimento; Avaliar o nível de conhecimento dos idosos a respeito das políticas públicas de saúde a eles destinadas.

\section{Impactos do Envelhecimento na Vida do Idoso: Aspectos Sociais, Psicológicos e Econômicos}

Até o século XIV a velhice era vista como um ato de mendicância, porque a principal característica do idoso nessa época era a de não poder manter-se financeiramente. Dessa forma, a imagem que se tinha do velho era a de não poder produzir. Assim, era denominado velho aquele que não era inserido na sociedade, embora se usasse o termo velhote para caracterizar o velho que tivesse sua imagem associada a um bom cidadão (ARAÚJO; CARVALHO, 2005).

Ainda para o mesmo autor, é possível perceber nos dias de hoje que é negado ao idoso o seu papel na sociedade, pois aconselhar e lembrar são atitudes atualmente rejeitadas sendo remetidas à velhice, mas de uma forma opressora.

O envelhecimento é um processo normal, representa uma fase da vida onde ocorrem mudanças físicas, psicológicas e sociais. Tais transformações acontecem de forma particular em cada indivíduo que envelhece. É um período em que o idoso faz uma análise de sua própria existência e chega à conclusão que alcançou muitos objetivos, mas também sofreu muitas perdas e a saúde representa uma delas (MENDES et al.,2005).

Desde o nascimento e ao longo da vida as pessoas estão sempre em contato com outras, se inserem em grupos e desempenham várias funções sociais. A prática de atividades e as relações sociais estabelecidas contribuem para reforçar a autoestima, o sentimento de valor próprio e facilita a adequação do idoso às perdas sofridas (LUZ; AMATUZZI, 2008).

A sociedade ainda não está preparada para acolher o papel social do idoso, haja vista que muitos se encontram em condições mínimas de sobrevivência. Grande parte dos idosos sofre com estereótipos e problemas sociais relacionados à sua capacidade de subsistência (SCORTEGAGNA; OLIVEIRA, 2012). 
Nos países em desenvolvimento como é o caso do Brasil, o acelerado envelhecimento da população agrega-se a outros aspectos sociais não resolvidos, como é o caso da pobreza e da exclusão, para muitos essa realidade de exclusão os acompanha por todo o percurso de suas vidas e na velhice de forma mais acentuada, na fase em que pensavam eles seriam respeitados, pelo contrário acabam tornando-se vítimas de uma sociedade opressora (SCORTEGAGNA; OLIVEIRA, 2012).

Para Simson, Neri e Cachioni (2006), o envelhecimento pode ser encarado como uma categoria social e afirmam que grupos sociais organizados sob princípios industriais capitalistas são danosos à velhice. Nessas sociedades o idoso passa a ser desvalorizado por não poder produzir mais de acordo com a demanda que o mercado exige. Por isso, o envelhecimento passa a ser não somente um processo psíquico ou biológico, mas também social.

Ainda de acordo com Simson, Neri e Cachioni (2006, p.107):

(...) nossas faculdades mentais, para continuarem vivas, dependem de nossa atenção à vida, do nosso interesse pelas coisas, enfim, dependem de um projeto. De que projeto o velho participa agora? (...) Durante a velhice, deveríamos estar ainda engajados em causas que nos transcendem,que não envelhecem, e que dão significado a nossos gestos cotidianos. Talvez seja esse um remédio contra os danos do tempo.

O apoio social é algo motivador para a pessoa idosa poder viver por mais tempo com autonomia e passar por o processo de envelhecimento com qualidade de vida, sem tantos problemas. Segundo Areosa, Benitez e Wichman (2012), os idosos que fazem parte de grupos sociais e que recebem incentivo social informal, são os que apresentam melhor saúde física e mental. A família é o principal meio de incentivo social.

Além das mudanças físicas, o envelhecimento causa uma série de alterações psicológicas, que podem ocasionar: dificuldade de enfrentamento de novos papeis, falta de motivação para planejamentos futuros, depressão, baixa autoestima, dificuldades de se adaptar às perdas orgânicas e afetivas (LIMA; DELGADO, 2010).

De acordo com o aspecto psicológico a velhice representa a última fase do ciclo vital, além de ser uma etapa da vida em que acontecem perdas muito significativas, tais como o surgimento de doenças crônicas, a morte do cônjuge, a perda de funções sociais, dificuldades financeiras decorrentes da ausência de trabalho e da aposentadoria, todos esses fatores resultam em isolamento do idoso e afetam a sua autoestima (SILVA; FOSSATTI; PORTELLA, 2007).

Porém, o envelhecimento não traz somente doenças e exclusão. O idoso tem capacidade para mudar as situações do decorrer de sua vida e para mudar a si mesmo. O idoso pode se sentir realizado e feliz no meio familiar e social. Hoje, muitos estudiosos voltam suas pesquisas para se chegar cada vez mais ao envelhecimento ativo e bem sucedido (LUZ; AMATUZZI, 2008). 
A velhice é uma fase do desenvolvimento humano tão importante quanto às outras e por isso merece respeito e dedicação, tanto dos estudiosos do assunto quanto da sociedade e o mais importante do estado, que é o responsável pelo planejamento de políticas públicas que venham promover a saúde e o bem estar da pessoa idosa (ARAÚJO; CARVALHO, 2005).

Na terceira idade a função física tem uma influência maior na qualidade de vida do que as alterações psicológicas, no entanto, estas não devem ser ignoradas. A aposentadoria é um dos principais fatores que causam esse tipo de alteração, porque remete a um sentimento de desvalorização e pode representar do ponto de vista psicológico, uma perda de identidade profissional (ALVARENGA; BITENCOURT; WANDERLEY, 2008).

Para Mendes et al., (2005), a aposentadoria foi criada como uma instituição para assegurar aos indivíduos uma renda até a morte, tendo em vista a necessidade de uma segurança individualizada. No início os idosos sentem-se realizados, pois a tomam como um período para descansar, com o passar do tempo descobrem um sentimento de tristeza e inutilidade.

O trabalho tem um espaço importante na existência do ser humano, é ele quem regula as ações do cotidiano da vida. Quando há perda desse vínculo acontece, além de desequilíbrio emocional, um determinismo para adoção de hábitos prejudiciais, tais como: atitudes sedentárias, dependência de álcool e alimentação inadequada (CANIZARES; JACOB FILHO, 2011).

Um forte aspecto geralmente visto nas pessoas idosas é que são pessoas desprovidas de uma fonte de renda e com baixo grau de instrução, isso torna menos viável o acesso a serviços médicos e sociais. As dificuldades que existiam no passado para que pudessem ter acesso à alfabetização, é hoje talvez a causa pelas quais os idosos sejam tão receptivos a programas de educação em saúde (LIMA; DELGADO, 2010).

Ainda para o mesmo autor, são muitos os fatores que acabam excluindo os idosos da sociedade, a própria aposentadoria, levando em consideração o ponto de vista econômico, não é capaz de suprir as suas demandas, notadamente as dos mais pobres, que em geral já têm alguma doença associada a incapacidades.

Para Nunes et al., (2010), a grande maioria dos idosos ganham em média um salário mínimo e gastam aproximadamente um quarto desse valor com medicamentos, comprometendo assim sua qualidade de vida.

Além das necessidades dos idosos, vêm também as da família. Para Gonçalves et al.,(2006), é possível observar que famílias carentes ou que se aproximam da linha de pobreza que vivem com seus idosos, são diretamente dependentes da renda destes para sobreviverem, constatação esta que denuncia uma realidade comum e ao mesmo tempo contraditória: o idoso que no seu contexto familiar não é valorizado, mas que passa a ser o provedor, o "chefe de família". 


\section{O Papel da Família no Cuidado com o Idoso}

Para a população idosa, os valores culturais são marcados pelo papel da família, que é vista pelo idoso como o seu habitat natural. A relação da pessoa idosa com sua família é de extrema importância em todo o decorrer de sua vida (JEDE; SPULDARO, 2009).

Para Mota et al., (2010), família é um termo amplo que tem vários sentidos. Entende-se família como um sistema social, cuja composição se dá por duas ou mais pessoas que vivem dentro de um mesmo contexto de afeição mútua, responsabilidade compartilhada e duração temporária. Tem como característica o compromisso, decisões conjuntas e objetivos divididos.

O planejamento das ações que envolvem o cuidado e a compreensão de questões psicológicas e sociais com as quais se deparam os idosos deve ser realizado dentro do seio familiar. A família foi durante muitos anos e continua sendo um apoio de grande importância para os idosos, como também, os familiares já idosos dispensam apoio e cuidados aos mais jovens (SMELTZER et al.,2009).

As famílias nas últimas décadas passaram por inúmeras transformações, como consequência estão menores e com um número maior de idosos. Isso porque as pessoas mais velhas estão vivendo mais resultando em uma convivência entre gerações mais prolongada. $\mathrm{O}$ fato das famílias hoje estarem menores, traz a tona a necessidade de se rever o amparo familiar que é disponibilizado para o idoso, visto que quanto menor o número de pessoas, esse suporte pode ficar mais limitado (SANTOS; PAVARINI; BARHAM, 2011).

No domicílio, o cuidado ao idoso é prestado geralmente por um cuidador familiar, que pode ser alguém da família, sem formação profissional na área da saúde, que está dando assistência ao ente familiar, ou ainda, uma pessoa da comunidade que foi ao longo do tempo ganhando experiência por cuidar de pessoas doentes e faz desse papel uma ocupação informal (FLORIANO et al.,2012).

Conforme Pimenta et al., (2009), um dos entraves que atrapalha o cotidiano de grande parte das famílias cuidadoras é a dificuldade financeira da parcela mais pobre da população. Muitos cuidadores sobrevivem da aposentadoria do idoso, que muitas vezes não consegue suprir nem mesmo as dificuldades do próprio idoso, especialmente aqueles que sofrem de demência, pois necessitam de cuidados especiais e submete o cuidador a uma carga de estresse elevada.

Nesses casos é importante que o cuidador seja orientado para lidar com essas situações e é necessário também que ele tenha um suporte social para cuidar da própria saúde, não havendo esse suporte, o cuidador fica sujeito ao risco de adoecer, não pelo trabalho do cuidado, mas pela sobrecarga a que é submetido (PIMENTA et al.,2009).

A velhice pode ser considerada um período de crise, porque envolve mudanças em todos os aspectos: biológicos, psicológicos, sociais e requer tanto da pessoa que envelhece como daquelas que 
com ela habitam adaptações a este momento da vida. Tais adaptações irão depender das relações de afeto criadas pelos entes ao longo da convivência (SOUZA; SKUBS; BRÊTAS, 2007).

O papel da família segundo Jede e Spuldaro (2009), é de extrema relevância no cuidado do idoso e é a principal alternativa quando da prestação de cuidados informais, porém é importante ressaltar que, mesmo sendo fundamental o cuidado da família, não abrange todos os idosos.

A Constituição Brasileira, no tocante a função da família, assinala o dever dos pais de dar assistência, criar e educar os filhos pequenos e os filhos maiores têm o dever de amparar os pais na velhice, doença ou em casos de necessidades destes. Enfatiza também o compromisso da sociedade e do estado, aliado à família de ajudar as pessoas idosas e que isto deve ser feito principalmente nos domicílios (SOUZA; SKUBS; BRÊTAS, 2007).

Segundo o Ministério da Saúde, o cuidado realizado no domicílio possibilita ao idoso o convívio familiar, reduz o tempo de internação hospitalar e as complicações provenientes dessas internações (FLORIANO et al.,2012).

É importante para os idosos que eles permaneçam em seus lares com suas famílias, o maior tempo possível e com o maior grau de autonomia que puderem obter. O suporte da família é essencial para que a pessoa idosa tenha um cuidado de qualidade (SALGUEIRO; LOPES, 2010).

\section{Método}

Trata-se de um estudo exploratório, descritivo, com abordagem qualitativa. Conforme Minayoet al., (2002), a pesquisa qualitativa responde a questionamentos muito singulares. Preocupa-se com tendências históricas, com um tipo de realidade que não pode ser colocada em números. Trabalha com significados, desejos, crenças e valores, aplicando-se de modo profundo ao interior das relações. Objetiva trazer dados subjetivos, que não podem ser reduzidos a estatísticas.

As pesquisas descritivas têm como principal objetivo descrever as características de um grupo ou fenômeno, ou ainda o estabelecimento de relações entre variáveis (GIL, 2002).

Para Lakatos e Marconi (2006), os estudos exploratórios são investigações de pesquisa empírica, ou seja, sem uma comprovação científica, cujo objetivo principal é o levantamento de questões ou de uma problemática, com três interesses: criar hipóteses, expandir a familiaridade do pesquisador com o meio para a realização de uma pesquisa futura mais precisa.

A pesquisa foi realizada na Unidade Básica de Saúde (UBS) do bairro Paraná, no Município de Iguatu/Ceará. O município situa-se na região Centro-Sul do Ceará, distante $380 \mathrm{~km}$ da capital do 
Estado Fortaleza. Apresenta uma área de $1029,002 \mathrm{~km}^{2}$, contando com uma população de 98,138 habitantes de acordo com o IBGE (2012). Apresenta clima tropical quente semiárido com temperaturas que variam entre $20^{\circ} \mathrm{C}$ e $35^{\circ} \mathrm{C}$.

O município é referência para os centros regionais no comércio e serviços oferecendo apoio para mais de 10 municípios circunvizinhos. Sua economia é baseada na agricultura e pecuária. $\mathrm{Na}$ esfera artística e cultural o município tem como principal festa a da padroeira da cidade Nossa Senhora Santana, além de serterra natal dos músicos e compositores Eleazar de Carvalho, Evaldo Gouveia e Humberto Teixeira.

O município de Iguatu conta com 25 Unidades da Estratégia Saúde da Família (ESF), onde 14 localizam-se na zona urbana e 11 na zona rural, sendo responsáveis pela atenção primária, a qual representa o contato inicial dos usuários nos serviços de saúde sendo considerada porta de entrada e referência para as Redes de Atenção à Saúde. (BRASIL, 2012).

A Estratégia Saúde da Família do Bairro Paraná é composta por 01 médico, 01 enfermeiro, 05 agentes comunitários de saúde, 01 dentista e 02 técnicos de enfermagem. A unidade é localizada na zona urbana e atua conjuntamente com mais duas unidades, Bairro Flores e Brasília.

O lugar foi escolhido por possuir um grande número de idosos que se reúnem semanalmente para atividades de educação em saúde, tornando assim mais acessível à coleta dos dados.

\section{Sujeitos do Estudo}

A pesquisa foi desenvolvida com 10 idosos que atenderam aos critérios de seleção da pesquisa.

Os critérios de inclusão foram: a) Possuir idade acima de 60 anos; b) Pertencer à área de abrangência da ESF do bairro Paraná; c) Participar do grupo de idosos; d) Aceitar espontaneamente assinar o Termo de Consentimento Livre Esclarecido (TCLE).

Foram excluídos da pesquisa os idosos que não se enquadraram nos requisitos acima citados.

\section{Instrumento de Coleta de Dados}

No intuito de alcançar os objetivos da pesquisa, os dados foram coletados através de uma entrevista semiestruturada (APÊNDICE A). As questões abordaram de início dados socioeconômicos, seguidas de questões norteadoras sobre a temática em questão. 
A entrevista é um encontro entre duas pessoas, objetivando que uma delas alcance informações acerca de determinado assunto, por meio de uma conversação de natureza profissional. É um procedimento usado na investigação para coletar dados sociais ou ainda para dar suporte no diagnóstico ou tratamento de um problema social (LAKATOS; MARCONI, 2006).

Para Minayoet al., (2002), a entrevista semiestruturada articula a possibilidade de o pesquisador abordar o tema proposto de forma livre, bem como fazer uso de perguntas previamente elaboradas, seguindo um roteiro.

A coleta foi realizada durante os meses de junho e julho de 2013, os dados foram coletados com o auxílio de um gravador, foi assegurado aos entrevistados o anonimato da entrevista, após a autorização os dados foram transcritos e detalhados.

As informações obtidas mediante as entrevistas foram transcritas na íntegra e analisadas de acordo com a técnica de Análise de Conteúdo de Bardin.

Segundo Bardin (2002) a análise de conteúdo é considerada um conjunto de técnicas de análise de comunicação que contém informações sobre o comportamento humano atestado por uma fonte documental. O objetivo da análise de conteúdo consiste em compreender criticamente, o sentido das comunicações, seu conteúdo, suas manifestações, as significações.

Para Bardin (2002), o processo de análise de conteúdo pode ser dividido em três fases: préanálise, exploração dos resultados e interpretação dos mesmos.

A pré-análise consiste na organização do material que foi submetido à análise. Correspondendo a um período de intuições, contudo, tem como objetivo tornar operacionais e sistematizar as idéias iniciais, levando a condução de um esquema preciso do desenvolvimento das operações sucessivas, num plano de análise. Essa fase possui três missões: a escolha dos documentos submetidos à análise, a formulação das hipóteses e dos objetivos e a elaboração de indicadores que fundamentem a interpretação final (BARDIN, 2002).

A segunda etapa, exploração dos resultados consiste na realização das decisões tomadas na pré-análise. É o momento da codificação - em que os dados brutos são transformados de forma organizada e agregados em unidades, as quais permitem uma descrição das características pertinentes do conteúdo. A última fase do processo de análise de conteúdo proposta por Bardin (2002), a interpretação dos resultados baseia-se literalmente em interpretar os resultados encontrados e articulálos com a literatura pertinente.

O estudo cumpriu os critérios previstos pela Resolução 196/96 Conselho Nacional da Saúde/Ministério da Saúde, que aborda as pesquisas envolvendo seres humanos (BRASIL, 2012).

Para garantir o anonimato dos idosos entrevistados, foram usados pseudônimos para identificá-los. Sendo assim, foram caracterizados com nomes de flores.

Id en line Revista de Psicologia. Ano 8, No. 22, Fevereiro/2014 - ISSN 1981-1179.

Edição eletrônica em http://idonline.emnuvens.com.br/id 


\section{Análise e Discussão dos Dados}

Após a realização das entrevistas e transcrição das falas dos idosos, os dados foram agrupados em categorias a fim de tornar o entendimento mais compreensível. Os resultados e a discussão serão relatados a seguir em duas etapas apresentando, respectivamente, as características pessoais e socioeconômicas dos entrevistados e o conteúdo dos eixos temáticos abordados na pesquisa.

\section{Caracterização dos Sujeitos}

A seguir serão apresentados os dados que se referem à idade, gênero, estado civil, familiaridade, escolaridade e renda familiar dos entrevistados. Os mesmos foram agrupados em tabelas fornecendo os percentuais de cada valor absoluto adquiridos através da pesquisa, e posteriormente, relacionados a literaturas pertinentes ao assunto abordado.

No que diz respeito à faixa etária, o estudo mostra que 05 (50\%) dos entrevistados têm entre 70 e 80 anos de idade, 03 (30\%) têm entre 80 e 90 anos, 02 (20\%) têm entre 60 e 70 anos (tabela 1).

Esses dados divergem do estudo de Brito et al., (2013), que diz que a faixa etária que mais cresce no mundo é a de indivíduos com 80 anos ou mais. No Brasil, enquanto a taxa média de crescimento por ano da população idosa, de 60 anos ou mais, é de aproximadamente 3,3\%,entre os idosos mais velhos é de 5,4\%, representando uma das mais altas.

Uma pesquisa divulgada a partir do Atlas do Desenvolvimento Humano no Brasil 2013 pelo Programa das Nações Unidas para o Desenvolvimento (PNUD) tendo como base os dados do IBGE (Instituto Brasileiro de Geografia e Estatística) 2010 mostrou que nos últimos 20 anos a expectativa de vida aumentou 14\%. As cidades com melhor expectativa de vida estão em Santa Catarina, onde o brasileiro vive em média 78 anos, 4 anos a mais do que a média brasileira e 5 anos a mais do que a média cearense, ambas respectivamente de 74 e 73 anos (PNUD, 2013).

Tabela 1- Perfil dos Participantes quanto à idade

\begin{tabular}{ccc}
\hline IDADE & VALOR ABSOLUTO & PERCENTUAL (\%) \\
\hline 60 A 70 & 2 & $\mathbf{2 0 \%}$ \\
70 A 80 & 5 & $50 \%$ \\
80 A 90 & 3 & $30 \%$ \\
\hline TOTAL & 10 & $100 \%$ \\
\hline
\end{tabular}

Fonte: Pesquisa direta, Iguatu-Ce, 2013. 
O envelhecimento populacional brasileiro tem sido um grande desafio para a saúde pública, uma vez que, essa transição demográfica trouxe consigo mudanças no padrão de saúde doença da população com uma maior prevalência das doenças crônicas não transmissíveis. Portanto se faz necessário atentar não só para o fato de que a população está envelhecendo, mas também para a qualidade desses anos.

No que concerne ao gênero, foram entrevistados 10 idosos, sendo 08 (80\%) do sexo feminino e $02(20 \%)$ do sexo masculino (tabela 2). Esses dados corroboram com o estudo de Figueiredoet al., (2007), que afirmam que as mulheres constituem a maior parcela da população idosa mundial e quanto mais a idade avança, mais elas se tornam a maioria, dessa forma, segundo o autor, o envelhecimento passa a ser um fenômeno antes de tudo, baseado no feminino.

Um estudo realizado por Camarano e Pasinato (2004), diz que essa predominância de mulheres na população idosa tem um impacto importante nas demandas por políticas públicas de saúde, porque, embora as mulheres vivam mais do que os homens, elas estão mais propensas a deficiências físicas e mentais do que estes.

Tabela 2 - Perfil dos participantes quanto ao gênero

\begin{tabular}{ccc}
\hline GÊNERO & VALOR ABSOLUTO & PERCENTUAL (\%) \\
Masculino & 2 & $20 \%$ \\
Feminino & 8 & $80 \%$ \\
\hline TOTAL & $\mathbf{1 0}$ & $\mathbf{1 0 0 \%}$ \\
\hline
\end{tabular}

Fonte: Pesquisa direta, Iguatu- Ce, 2013.

A velhice afeta de forma diferente homens e mulheres, portanto a questão de gênero deve ser encarada como um determinante da saúde e da qualidade de vida dos idosos, fazendo-se necessária a valorização dessa questão para uma melhor compreensão do processo de envelhecimento entre homens e mulheres.

Em relação ao estado civil houve predominância de mulheres viúvas $80 \%$ (tabela 3), o que vem a concordar com um estudo realizado por Baldin e Fortes (2008), onde eles mostram que o estado conjugal que prevalece entre as mulheres idosas é a viuvez, cerca de $41 \%$, seguidos de $39 \%$ casadas.Em contrapartida, $70 \%$ dos homens eram casados e apenas $13 \%$ viúvos, isso deve-se ao fato de que as mulheres têm uma maior longevidade e os homens tendem a casar novamente com mulheres mais jovens.

As mulheres uma vez viúvas, em sua maioria, passam a viver sozinhas ficando mais vulneráveis a depressão e a outros transtornos mentais que possam surgir provenientes da solidão. 
Um estudo desenvolvido por Gomeset al., (2013) destaca que o estado conjugal tem papel importante nos determinantes de mortalidade adulta. De modo geral, em países desenvolvidos os indivíduos casados vivem mais comparados aos divorciados, separados, viúvos e nunca casados. No Brasil, onde cada vez mais é possível observar pessoas em idades mais avançadas vivendo sozinhas esse tipo de estudo torna-se relevante.

Tabela 3: Perfil dos participantes quanto ao estado civil.

\begin{tabular}{ccc}
\hline ESTADO CIVIL & VALOR ABSOLUTO & PERCENTUAL (\%) \\
\hline Casado (a) & 2 & $20 \%$ \\
Viúvo (a) & 8 & $80 \%$ \\
\hline TOTAL & $\mathbf{1 0}$ & $\mathbf{1 0 0 \%}$ \\
\hline
\end{tabular}

Fonte: Pesquisa direta, Iguatu-Ce, 2013.

Identificar os riscos aos quais idosos estão expostos é sempre importante, dessa forma é possível estabelecer um planejamento capaz de assisti-los nas suas especificidades.

Com relação à familiaridade, a maioria dos idosos mora com os filhos 30\% e netos 30\%, $20 \%$ moram com o cônjuge e os outros $20 \%$ residem sozinhos. (tabela 4). O que vem a concordar com o estudo de Pedrazziet al.,(2010), que mostra que alterações socioeconômicas nos países latinoamericanos têm levado os filhos a morarem novamente com seus pais e a ficarem por mais tempo dependentes financeiramente.

A relação de troca entre gerações onde os pais idosos ajudam economicamente os filhos tem se tornado cada vez mais comum, a proporção de netos que moram com os avós também cresceu, nesses domicílios existe uma relação de extrema importância para os adultos, por terem alguém para cuidar de seus filhos (ARANTES et al., 2010).

Esses dados discordam do censo realizado pelo IBGE em 2010, que diz que a proporção das pessoas que moram sozinhas é um fenômeno resultante da combinação de vários fatores, dentre eles, o aumento da esperança de vida, fazendo com que os idosos venham a residir sozinhos, uma vez que não dividem mais o teto com parentes (IBGE, 2010). 
Tabela 4: Perfil dos participantes quanto à familiaridade.

\begin{tabular}{ccc}
\hline FAMILIARIDADE & VALOR ABSOLUTO & PERCENTUAL (\%) \\
\hline Sozinha (o) & 2 & $20 \%$ \\
Cônjuge & 2 & $20 \%$ \\
Filhos & 3 & $30 \%$ \\
Netos & 3 & $30 \%$ \\
Outros & 0 & 0 \\
\hline TOTAL & $\mathbf{1 0}$ & $\mathbf{1 0 0 \%}$ \\
\hline
\end{tabular}

Fonte: Pesquisa direta, Iguatu-Ce, 2013.

Apesar da melhora nas condições de vida e saúde dos idosos e da autonomia e liberdade que vêm conquistando com a longevidade, é importante que eles tenham com quem dividir o dia-a-dia, seja com os filhos, netos ou pessoas com quem não possuam laços sanguíneos. Velhice não é sinônimo de doença, mas a pessoa idosa está mais propensa a certos riscos que outros grupos etários, é necessário ter a quem recorrer quando da existência de algum problema.

Quanto ao grau de escolaridade dos idosos entrevistados a maioria 90\% (tabela 5), possui o ensino fundamental incompleto, esse é um dado relevante para o estudo, uma vez que, quanto mais baixo o nível educacional dos idosos, mais limitado se torna o acesso à informação, menor é a absorção de orientações necessárias à saúde e ao auto cuidado. Vale ressaltar que aumenta a responsabilidade do disseminador das informações, no caso do profissional de saúde que terá que lançar mão de meios e linguagem acessível para que as orientações atinjam os resultados esperados.

A baixa escolaridade limita também a defesa dos próprios direitos, o acesso à cultura, por isso é importante garantir que os idosos tenham oportunidade de estudar ao longo da velhice e incluí-los em programas culturais juntamente com indivíduos de outras faixas etárias.

Tabela 5: Perfil dos participantes quanto à escolaridade.

\begin{tabular}{ccc}
\hline ESCOLARIDADE & VALOR ABSOLUTO & PERCENTUAL (\%) \\
\hline Fundamental completo & 0 & 0 \\
$\quad$ Fundamental & 9 & $90 \%$ \\
incompleto & 1 & $10 \%$ \\
Médio completo & 0 & 0 \\
Médio incompleto & 0 & 0 \\
Superior completo & 0 & 0 \\
Superior incompleto & $\mathbf{1 0}$ & $\mathbf{1 0 0 \%}$ \\
\hline TOTAL & & \\
\hline
\end{tabular}

Fonte: Pesquisa direta, Iguatu-Ce, 2013. 
Desse modo os dados apresentados igualam-se aos do estudo de Prado (2006), que mostra que o grau de escolaridade dos idosos é baixo, especialmente entre as mulheres e o número de analfabetos é expressivo, representando 5,1 milhões de idosos, em 2004 o IBGE (Instituto Brasileiro de Geografia e Estatística) apontou um índice de 36,9\% para os indivíduos com mais de 60 anos de idade sem instrução e com menos de 1 ano de escolaridade. Se comparado com o número de analfabetos de pessoas com mais de 15 anos, que aparece na mesma fonte, que é de 11,6\% é perceptível a desvantagem em que os idosos aparecem, consequência da estrutura educacional oferecida no passado.

Até a idade média a educação pedagógica tinha o objetivo primeiro de formar o indivíduo que trabalharia na indústria, por isso, a educação escolar tomou como base essa metodologia pedagógica direcionada às primeiras fases da vida e assim as pessoas de mais idade foram sendo deixadas à margem desse projeto educacional porque produtivamente não interessavam mais. Isso explica em grande parte, a inexistência de um plano educacional destinado especialmente aos idosos, quando se leva em consideração o modo capitalista de educação (PERES, 2010).

No que diz respeito à renda familiar 5 idosos $(50 \%)$ ganham um salário mínimo, três $(30 \%)$ ganham dois salários mínimos, um idoso (10\%) ganha de dois a quatro salários mínimos e um idoso (10\%) ganha uma renda mensal inferior a um salário mínimo (tabela 6).

Esses dados assemelham-se ao estudo de Lima e Murai (2005), que diz que a população idosa brasileira é caracterizada pelo baixo poder aquisitivo, tendo nas aposentadorias e pensões sua principal fonte de renda. Além disso, quando se aposenta, o idoso sente menos medo da perda do emprego, sentindo-se amparado, ainda que pobre.

Um estudo realizado por Coutrim (2006) confirma os dados da pesquisa supracitada ao mostrar que a aposentadoria é uma possibilidade de maior segurança financeira na vida do idoso, embora esteja sujeito a inúmeros gastos com remédios e tratamentos de saúde, porém esse estudo afirma que mesmo a renda do indivíduo diminuindo após os 60 anos, a pobreza entre esse grupo etário diminuiu.

Ainda tem o fato de que muitos indivíduos, mesmo depois dos 60 anos, ainda continuam sendo os provedores da família, como mostra um estudo de Tavares et al., (2011) que afirma que pesquisas realizadas pelo IBGE (Instituto Brasileiro de Geografia e Estatística) evidenciaram que a colaboração do idoso na renda da família é cada vez mais significativa. Inicialmente na década de 80, a participação dos idosos era de 37\%; já, na década de 1990, pulou para 47,2\% e, em 2007, em 53\% dos domicílios com idosos, mais da metade da renda provinha de pessoas com 60 anos ou mais. 
Tabela 6- Perfil dos Participantes quanto a renda familiar

\begin{tabular}{ccc}
\hline RENDA FAMILIAR & VALOR ABSOLUTO & PERCENTUAL (\%) \\
\hline$<$ 1 Salário & 1 & $10 \%$ \\
1 Salário & 5 & $50 \%$ \\
2 Salários & 3 & $30 \%$ \\
2 a 4 Salários & 1 & $10 \%$ \\
\hline TOTAL & $\mathbf{1 0}$ & $\mathbf{1 0 0 \%}$ \\
\hline
\end{tabular}

Fonte: Pesquisa direta, Iguatu-Ce, 2013.

Portanto, a maioria dos idosos brasileiros além de garantirem o seu sustento, ainda mantêm a família. Psicologicamente o status de provedor deve ser algo que causa satisfação, porém financeiramente não é uma regalia, pelo contrário, a velhice em si já vem atrelada a uma série de modificações fisiológicas e muitas vezes patológicas que gera despesas, dessa forma, se torna muito oneroso para o idoso continuar tendo pessoas que dependam da sua renda.

\section{Categorias dos Idosos Entrevistados}

Os dados colhidos através das entrevistas foram agrupados em categorias e comparados às literaturas pertinentes ao assunto abordado com o intuito de alcançar os objetivos propostos pelo estudo.

\section{Conhecer a Visão dos Idosos Acerca do Significado da Velhice}

Nessa categoria objetivou-se conhecer o entendimento e opinião dos idosos acerca do próprio processo de envelhecimento.A maioria dos idosos se referiu à velhice como algo natural, e uma fase boa, sendo um privilégio, pois permanecem ativos, lúcidos e com saúde.

Eu acho que a velhice é uma coisa que a gente foi novo né, hoje assim, fiz um ano aí de ano em ano, fiz sessenta anos, estou com oitenta vou fazer oitenta e um, desses oitenta e um que eu já passei eu vivi muito bem, graças a Deus e tô indo tenho saúde. (Margarida)

É bom né a pessoa ficar velha, ficar lúcida, sabendo que tá vivendo e sabendo como é que tá as coisas ainda né, agora triste é a pessoa ficar velho e não saber mais o que tá se passando, a pessoa ficar idosa, ter seus filhos, seus netos e você tá sabendo que eles tão tudo ali com você em paz né. (Rosa) 
Eu sou feliz pela minha idade e tudo, eu sou evangélica, vou pra igreja é muito bom vai muita gente, eu tô bem. (Violeta)

Minha filha, pra mim tá sendo até boa, é porque eu tenho a minha saúde firme né, ainda tô entendendo alguma coisa, eu ainda faço crochê, ainda sei fazer comida do jeito que eu fazia quando era nova, ainda sei cuidar de uma casa, lavar minha roupa, a de ninguém não a minha, ainda lavo bem limpinha e tô vivendo né, mas num é muito boa não, porque é diferente da mocidade, daquele tempo, passeava, cuidava das coisas, hoje é mais diferente. (Orquídea)

Eu entendo que a velhice a gente sabe que todo mundo vai ter, feliz dos que fica velho e os que não fica a gente sabe que morre cedo, feliz de quem fica velho né e a velhice é coisa da vida, porque nasceu morreu. (Lírio)

A percepção da chegada da velhice está relacionada principalmente a aspectos negativos, porém a forma de pensar e os significados dados à velhice e ao envelhecimento são peculiares a cada idoso. A maioria dos entrevistados nesta pesquisa sente-se bem nessa fase de suas vidas.

Um estudo realizado por Guerra e Caldas (2010) pesquisou a percepção dos idosos acerca da velhice, o resultado do estudo compreendeu dois aspectos, um positivo que diz respeito à longevidade, ao acúmulo de experiências e à conquista de uma vida melhor com mais autonomia principalmente financeira e um negativo que se refere às alterações fisiológicas, aparecimento de doenças e as limitações inerentes a essa fase.

Uma pesquisa realizada por Schneider e Iragaray (2008) mostra dados de um estudo realizado em sociedades não ocidentais e estas apresentam imagens positivas da velhice e traz ensinamentos de que a ideia de velhice ligada à deterioração e perda não é universal. À medida que o envelhecimento vai sendo estudado entre outros povos, conclui-se que ele é um processo influenciado pela cultura ao qual se está inserido.

É possível observar nas literaturas a escassez de trabalhos que compreendam esse assunto de forma direta, uma vez que, cada idoso tem seu ponto de vista a esse respeito. A velhice nada mais é do que uma construção daquilo que o idoso viveu e isso inclui uma série de questões culturais, sociais, familiares. Talvez isso se atribua à ínfima quantidade de estudos que contemple esse aspecto do envelhecimento, o fato de que para isso é necessário o envolvimento de uma gama de questões.

Porém quatro dos idosos entrevistados associaram o envelhecimento à doenças, dor, conformismo como relatam a seguir:

A gente sofre né, mas que graças a Deus o que eu sofro mais é só dor, doença, essas coisas, perna doendo, cabeça doendo essas coisas assim, acho que isso é de quem é velho mesmo. (Açucena)

Ah! Minha filha vou te falar, o povo diz que eu tô na terceira idade, mas que terceira idade, eu tô é na quarta, olhe, menina, moça, mulher nova e velha, foi a mais ruim que eu encontrei foi essa de velha. (Flor-de-lis) 
A gente, agora faço como a história, viveu sempre aqueles tempo, vai vendo até o que dá pra ser né.(Bromélia)

A velhice por um lado, é uma coisa que a gente num pode nem entender né, porque o homem depois de velho é uma coisa que o mundo nem precisa mais dele, o novo tem tudo, mas o velho não é assim não, a velhice acaba muito com a pessoa. (Cravo)

Esses dados condizem com um estudo realizado por Lima e Murai (2005), onde ele ressalta que é muito comum a ideia de velhice associada à doença e à incapacidade. Em consequência disso, as questões sociais relevantes para os estudos sobre o envelhecer humano, são deixadas de lado, abrindo espaço para que além do desgaste físico, outras situações como o sentimento de exclusão, inutilidade, sejam vistos de forma natural. Esse estado de pouca importância do idoso significa a perda de sua dignidade, um não reconhecimento de seus direitos à igualdade, seja na saúde, moradia e outras condições necessárias para uma sobrevida dentro dos parâmetros de cidadania.

Refletir acerca do significado da velhice através de relatos dos idosos, é um mecanismo importante para que se possa compreender o real sentido do processo de envelhecer na vida dos mesmos. Dessa forma, os profissionais de saúde em especial o enfermeiro, podem criar mecanismos para promover a autonomia e independência do idoso, levando em consideração as alterações que ocorrem nesse período.

\section{Reações dos Idosos às Modificações que Ocorrem com o Avançar da Idade}

Para contemplar essa categoria, investigou-se como os idosos reagem às mudanças impostas pelo processo de envelhecimento. A maioria dos idosos as enxerga de forma negativa, com sentimento de inutilidade, resignação e medo relacionado à morte.

Quando eu era mais novo de tudo era mais fácil, de tudo, se é pra dizer o que é né, o que tem no mundo depende da juventude, a velhice num tem mais nada, de sessenta anos pra cá, depois que a gente se aposenta num tem mais emprego pro velho, ninguém quer mais velho pra trabalhar, lá nos mato pode o velho ainda fazer algum movimento, mas aqui na cidade o que é que ele faz? Nada, fica sentado nessa cadeira espiando o povo passando pra lá e pra cá. (Cravo)

Eu acho que eu tenho que me conformar e achar bom a velhice, porque a velhice nós tem com certeza, aí aquelas coisas que a gente tá aqui pensando na velhice nós tem que a gente aceitar o que aquele pai consentiu. (Margarida)

É porque agora faço como a história, assim é uma vivência que Deus deu que a gente for sadio vive bem, num sendo vai passando, de qualquer maneira a gente tem que viver até o dia que for possível. (Bromélia) 
A gente fica assim meio deprimida, agente fica com medo, com medo de deixar os filhos da gente, deixar a família, pois é, como eu já sofri agora uma irmã minha de cinquenta e seis anos bem novinha, mas nova do que eu muito né, pois é, mas a gente tem que ir pra frente. (Lírio)

Minha filha, o que mudou foi que quando eu era nova, eu trabalhava quanto mais eu trabalhava mais coragem eu tinha e agora meu trabalho é essa crochezinho aqui, daqui a pouquinho entro pra dentro me deito sem coragem e de tarde do mesmo jeito, até ontem a noite era os fogos da festa de Nossa Senhora Sant'ana e eu ah meu Deus se eu tivesse coragem de ir, se eu tivesse coragem de ir, não podia ir porque eu não tinha coragem, me dá logo um treme, me dá uma canceira, me dá uma dor de cabeça, eu tenho estalecido muito forte aí não dá pra mim ir. (Flor-de-lis)

Quatro dos idosos entrevistados demonstraram através de suas falas que as alterações ocorridas em suas vidas por causa da velhice são vividas com naturalidade e até de forma positiva apesar de algumas limitações.

Normal, porque ó, eu me lembro que quando minha sogra tava ficando velha ela ficava olhando assim e dizia eu num acredito, eu num acredito que minha pele tá ficando desse jeito e eu não tenho esse preconceito, graças a Deus eu não tenho. (Rosa)

Só é ruim pra andar no mundo, mas o resto tá normal. (Violeta)

Vivo bem graças a Deus, porque eu tenho meu aposento, eu tenho minha vida mais pra onde eu quiser ir eu vou, não tem quem mande na minha vida, assim deu querer ir um passeio na casa de uma filha, eu passei três meses em São Paulo na casa de uma filha minha, ela hoje é viúva. (Orquídea)

Não, hoje eu quase num notei nada não, porque hoje, até hoje eu tenho uma roça, trabalho na roça e sou agricultor, tô colhendo, vou tirar uma porção, só num vai porque uma vaca tá comendo a lavoura,mas hoje todo movimento eu faço no serviço da roça do jeito quando eu era novo, num faço como novo porque a gente num vai aforçar porque gente velho num pode aforçar no serviço, mas eu gosto de trabalhar, todos os anos eu trabalho, tá dentro parece que, num sei quantos anos de aposentado, eu aposentei em 91 já tá quase com 17 a 18 anos de aposento, mas eu nunca deixei de trabalhar na roça não. (Girassol)

Essa divergência de opiniões observadas nas falas dos entrevistados assemelha-se ao estudo de Fechine e Trompieri (2012), que afirma que o ser humano sempre deu importância ao processo de envelhecimento, enxergando-o de diferentes formas. Alguns acham que com a velhice há uma redução das capacidades para o desenvolvimento das atividades de vida diária, outros a caracterizam como uma etapa de crescentes riscos e vulnerabilidades e de grande dependência. Outros, ainda, consideram a terceira idade como a época de maior sabedoria, bom senso e ponderação.

Para Jardim, Medeiros e Brito (2006), quando a velhice está relacionada à doença, o idoso tende a considerá-la como algo negativo, mas isso também vai depender do contexto social e cultural em que vivem. Quando são instigados a contarem suas histórias de vida, acabam representando 
imagens mais positivas do envelhecimento. Para alguns idosos, mesmo com a existência de doenças, a velhice pode trazer alegria, pois o convívio com a família, filhos e netos, bem como a autonomia para realização de suas tarefas, é algo prazeroso. Esse pensamento dos autores citados pode ser evidenciado na seguinte fala:

Eu tô bem graças a Deus, moro aqui na minha casa, tenho minha casa, minha filha pra me fazer companhia quando tá em casa porque ela anda muito pra Fortaleza e tenho meu aposento minha pensão, dá muito bem pra me comer $e$ comprar minhas coisas e tá bom minha vida, se Deus quisesse que eu durasse mais, tem uma amiga minha aí do outro lado, que ela um dia disse me encontrei com ela, ela é da minha idade: vamo fazer um negócio com Deus, eu disse, diga lá, ela disse vamo fazer um negócio pra nós durar cem anos, aí eu tava dizendo que tava doente, aí a minha filha disse, mãe num fez o negócio com a mulher pra durar cem anos, eu disse: eu fiz com a mulher, mas não sei se Deus aceitou. (Flor-de-lis)

Por isso, o cuidado holístico é tão importante, olhar o outro de uma forma geral, o ser humano não é só um corpo físico, ao cuidar de um idoso é necessário que se leve em consideração não só as suas queixas físicas, mas conhecer o ambiente onde ele está inserido, uma vez que esse será determinante na maneira como ele irá encarar esse processo de envelhecimento.

O idoso que tem um bom contexto familiar, social e cultural, vai reagir às modificações que ocorrem com a chegada da velhice de uma maneira positiva, mesmo com as limitações existentes, em contrapartida, àqueles idosos que não contam com esse suporte vai encarar negativamente qualquer alteração que ocorra em suas vidas, inclusive as que ocorrem na terceira idade.

O envelhecimento é uma experiência sujeita a diversas influências e é preciso conhecê-las para que se possa prestar uma assistência ao idoso humanizada e livre de preconceitos.

\section{Sentimentos Atribuídos pelos Idosos ao Processo de Envelhecimento}

Nessa categoria foi questionado aos idosos sobre os sentimentos que eles têm em relação à velhice. Foi possível notar nas falas da maioria que os principais sentimentos atribuídos foram aceitação, alegria e estabilidade emocional frente às modificações.

Não, eu não tenho sentimento da velhice, eu vivo aqui é cantando, porque a morte é uma coisa certa, quando nós somos novo, nós temos medo da morte que se pela, mas depois de velho num é assim não, sabe que morre pra que ter medo.(Cravo)

Não, eu num tenho quase sentimento, porque o camada, a velhice a gente tem que ficar na idade, tem que ficar velho, mas é assim mesmo.(Girassol) 
Não, é isso mesmo, agora só que a gente vive os tempo que Deus quer, ás vezes é doente e dura muito e outros é sadio e no instante morre né. (Bromélia)

Tem gente que diz: ah porque eu sou velha num sei o que fica se reclamando, eu graças a Deus num tenho nenhuma reclamação por causa da idade não. (Rosa)

Assim porque, eu acho que a velhice ela, quando a gente tá de setenta ano pra lá, já vem trazendo muita coisa que a gente passou, já passou, o que a gente sente hoje é o que eu senti e passei quando eu era nova, tudo aquilo vou juntando, vai juntando, aí vai ficando ali né, esperando a velhice chegar, solidão eu não quero, eu não sinto não porque quando eu tô só eu já tô é saindo, olhe a solidão é a tristeza do mundo, você tá aqui sozinha assentada ali na cadeira, num pode fazer isso, de jeito nenhum, porque a pessoa que fica ali triste, ali num lugar, aquilo ali aí vai e causa muita coisa ruim. (Margarida)

Esses dados assemelham-se a um estudo feito por Vilela, Carvalho e Araújo (2006) que demonstrou que a maioria dos idosos entrevistados tinha sentimentos de satisfação, aceitação e alegria com a chegada da terceira idade, comentaram ainda que se sentiam amados pela família e que faziam o que gostavam, para eles alcançar a velhice era uma dádiva.

Um estudo realizado por Santos (2008) também concorda com os dados da pesquisa quando ele diz que investigações tendem a afirmar que sentimentos como a solidão diminui com a idade, isso não quer dizer que as pessoas idosas não tenham esse tipo de sentimento, mas talvez porque os jovens tenham uma maior necessidade de falar sobre isso, pois passam por muitas transições. À medida que a idade vai aumentando, a vida social tem uma tendência a estabilizar, quanto mais anos vividos, mais habilidades sociais.

Um estudo realizado por Guerra e Caldas (2010) interrogou os idosos sobre suas representações diante do processo de envelhecimento, os autores disseram não perceber frustrações, conflitos e drama na maneira como eles lidavam com a velhice, tampouco foram evidenciados sentimentos de rejeição ou inferioridade frente às mudanças.

Silvaet al., (2012) apontam para o fato de que para cada idoso a velhice apresenta algo diferente, observa-se que alguns reconhecem nesse processo oportunidades de ganhos, como sentimentos de integridade e satisfação com a vida. No entanto, alguns idosos têm medo de envelhecer e tornarem-se pessoas dependentes, sozinhas, inativas e até mesmo medo da própria morte. Embora a velhice nem sempre esteja associada a doenças, o aumento de fatores de riscos e o temor das perdas relacionadas à saúde ocupam lugar prioritário nas preocupações dos idosos. Como relatam a seguir:

Eu só acho ruim ser velha porque eu não posso andar na casa da minha família, não posso ir mais no meu terreno que eu tenho no sítio, não posso mais ir lá, chamo um genro num vai porque tá ocupado, chamo outro num vai, chamo uma filha aí diz ai meu carro num passa naquelas estradas, num dá pra ir não. (Flor-delis) 
Eu acho que a velhice devia não ter, mas tem que ter porque a gente não pode ficar mais novo, mas eu acho que a velhice faz parte da vida, pois é, é uma coisa que todos nós vamos ter, os que não morrerem logo né, porque vem doença aí pra frente, sei que a gente não vai viver pra sempre, mas sei que vem doenças aí que mata até os novo como você sabe que tem né e que não há remédio, você sabe que tem. (Lírio)

O contexto do envelhecimento envolve sentimentos positivos e negativos. Tais sentimentos estão na maioria das vezes ligados a experiências pregressas, aqueles idosos que conviveram com figuras paternas e matrimoniais que bloqueavam suas vontades e que tinham obrigações que lhe roubavam todo o tempo, sem dúvida devem valorizar o sentimento de liberdade de ir e vir e de ter seus próprios desejos. Vale ressaltar que eles não guardam mágoas pelo tempo que passou, mas alegria por uma nova fase alcançada, na verdade, um privilégio.

\section{Visão dos idosos sobre a participação familiar no processo de envelhecimento}

Quando questionados sobre a importância da família nessa fase de suas vidas, todos os idosos foram unânimes em atribuir sentimentos positivos como, união, segurança, amor.

Considero muito importante, graças a Deus, porque muita gente aqui dentro desse Iguatu, meus vizinhos mesmo se admira porque meus filhos anda na minha casa direto, graças a Deus que quando eles nasceram já foi, nós tudo fumo unido graças a Deus. (Margarida)

É, porque nós sem a família num vale nada, tem que ser é formado com os filhos né, porque uma pessoa não vive só, é preciso ter a formação de qualquer uma palavra né, precisa de uma coisa tem um filho que faça. (Girassol)

É, é importante, porque você tendo sua família tudo ao redorzim de você, você se acha que não vai acontecer nada com você né, tá todo mundo ali perto, é no caso meu né, meu filho que mora lá em Fortaleza, mas ele todo dia ele liga, todo dia ele pergunta como é que eu tô, aí agora ele não pôde vir, mas mandou a mulher e os dois filhos, aí é muito importante assim né, a presença deles na casa da gente, vem com aqueles carinho aqueles amor com a gente, é bom demais.(Rosa) (Flor-de-lis)

Graças a Deus, se não fosse a minha família eu não era nada, acredita?

Eu acho, ai de mim se não fosse meus filhos, eu amo meus filhos sabe, eles são muito importantes na minha família. (Lírio)

Minha família é compreendida, faz tudo no jeito, num precisa de eu tá gritando ninguém, aqui em casa não existe revolta, somos eu e quatro filhos, mas ninguém vê briga aqui em casa, se eu arranhar com um filho meu é lá dentro só eu e eles. (Cravo) 
Esses dados coincidem com um estudo realizado por Rissardoet al., (2011) que diz que no que concerne à família, a palavra união foi a mais usada pelos idosos para descrevê-la. Para esses idosos o mais importante é a família conviver unida.

Outro estudo feito por Porto (2005) confirma esses dados, quando os idosos foram interrogados a respeito do que consideravam serem necessidades específicas de suas faixas etárias, a maioria respondeu que o mais importante é o convívio carinhoso com a família.

Infelizmente essa realidade nem sempre chega a todos os idosos. Para Camarano e Kanso (2010), embora as leis brasileiras estabeleçam que o cuidado dos idosos dependentes deva ser de responsabilidade da família, isto muitas vezes não ocorre passando esta a requerer do estado ou das instituições privadas a divisão das responsabilidades na assistência a população idosa, dessa forma a alternativa são as instituições de longa permanência para idosos (ILPIs), sejam públicas ou privadas.

Porém a percepção dos idosos institucionalizados a respeito de família é diferente da opinião daqueles que convivem com os parentes, filhos e netos. Um estudo realizado por Oliveira et al.,(2006) com idosos residentes de uma instituição de longa permanência indagou sobre os sentimentos dos mesmos em relação a sua família, a maioria respondeu que sente saudade e quando questionados sobre o que achavam que a família poderia fazer para melhorar as suas condições de vida, a grande maioria respondeu que a família nada poderia fazer por eles, provavelmente magoados por terem sido deixados ali. O estudo ainda revelou que grande parte dos que lá residiam tinham sido internados involuntariamente.

A família é a estrutura mais importante na vida do ser humano, é o alicerce, é a partir da formação da família que se finca raízes, cria-se identidades, adquire-se valores. Para os idosos, a família é uma garantia de continuidade, é o prosseguimento a partir dos ensinamentos que eles com muita dificuldade na maioria das vezes repassaram. Para a grande maioria deles a vida não foi fácil e criar os filhos, educá-los dentro das possibilidades que tinham era um grande desafio. Por isso, quando velhos, o mínimo que esperam é que possam ser cuidados e amados pela família a quem eles se dedicaram a vida inteira.

A legislação brasileira garante isso através da Constituição Federal e do Estatuto do Idoso, que diz que é obrigação dos filhos maiores prover os cuidados necessários para com o idoso, porém não se espera normalmente que um pai tenha que recorrer judicialmente para que lhe seja garantido à atenção dos filhos.

Por outro lado, não é por os idosos estarem nas casas de familiares com uma pessoa cuidando deles, que não precisem, principalmente os mais frágeis, de demonstração de apoio e amparo.

Um estudo realizado por Fernandes (2008) mostrou que é justamente porque a família é incumbida de atender às necessidades dos idosos que eles precisam ter acesso à informação e orientação sobre os cuidados corretos. 
É nesse contexto que se faz necessária a presença de profissionais que trabalham com a saúde dos idosos realmente comprometidos e atuantes, que orientem e esclareçam as dúvidas dos familiares e cuidadores, que façam visitas aos idosos, que busquem conhecer o seu convívio, que estimule a criação de atividades que beneficiem a integração social do idoso. Vale ressaltar que mais importante do que a formulação de políticas públicas é colocar em prática as já existentes.

\section{Nível de conhecimento dos idosos a respeito das políticas públicas de saúde a eles destinadas}

Nesta categoria foi questionado aos idosos sobre os seus conhecimentos a respeito das políticas de saúde criadas para atender as suas necessidades. A maioria como demonstra as falas, não têm conhecimento acerca do assunto, outros ficam em dúvida ao afirmarem conhecer algo a respeito, somente um idoso falou com convicção de uma política pública de saúde, de modo geral, há um profundo desconhecimento dos gerontes sobre o assunto.

Não. (Bromélia)

Não, eu num sei não (Açucena)

Bom, se tem esse negócio aí eu não sei. (Cravo)

Nunca vi não, eu quase num assisto televisão. (Girassol)

Já, em alguns lugares, mas aqui no Iguatu, acho que tem.(Lírio)

Tem essa nossa né, a caminhada. (Rosa)

Assim, nos remédios, até agora pode mudar né, eu também tenho diabetes, tenho os remédios dados pelo governo e pressão alta, agora ainda num precisei foi fazer ultrassom, mas tudo é por conta do governo, é uma boa coisa, agora tá aparecendo às mudanças, eu só faço por conta do governo porque a minha ajuda é pouca, quer dizer a de todo mundo, mas tem gente que tem mais ajuda do que eu, eu tenho o meu salariozinho só e pronto, num da pra tudo não. (Orquídea)

Corroborando com os dados do estudo, Fernandes (2008) diz que é fato os idosos não terem conhecimento sobre estas questões, por isso é importante que essa tarefa seja assumida pelos profissionais que a eles prestam assistência. Inserir esse tipo de conteúdo nas atividades é essencial, porque as políticas de saúde para o idoso só progredirão se houver mobilização da sociedade, profissionais e principalmente dos idosos.

Esse achado pode está diretamente associado ao baixo nível de escolaridade dos idosos, o que influi na maneira de assimilar determinados assuntos como este. 
Um estudo realizado por Silva (2013) que pesquisava o nível de conhecimento de idosos acerca do estatuto do idoso verificou que a maioria desconhecia o estatuto e evidenciou uma associação entre escolaridade e conhecimento sobre o mesmo, ou seja, quanto menor o grau de instrução, maior o desconhecimento a respeito do assunto.

Por outro lado, um estudo feito por Martins e Massarollo (2010) com 63 idosos do município de São Paulo, mostrou que $31(49,2 \%)$ conheciam sobre o assunto e diziam saber sobre seus direitos, $11(17,5 \%)$ disseram que não conheciam 19 (30,2\%) afirmaram não saber acerca dos seus direitos, um $(1,6 \%)$ não opinou e um $(1,6 \%)$ disse não lembrar. O mesmo estudo ainda revelou que apesar do direito a saúde ser garantido por lei, na opinião dos idosos, nem sempre eles são respeitados.

Para que os direitos dos idosos sejam valorizados é necessário antes de tudo que se conheça sobre eles para que possam ser cobrados. Infelizmente os estudos mostram que os idosos que têm uma consciência política são aqueles que detêm um melhor nível educacional. Um estudo realizado por Mafraet al., (2010) mostra que mais da metade da população com 60 anos ou mais (52\%) alfabetizada vive na região sudeste, o que justifica o estudo supracitado. Em seguida, vêm às regiões nordeste e sul com $19 \%$ e $18 \%$ respectivamente. Já nas regiões norte $(5,60 \%)$ e centro sul $(5,40 \%)$ é onde estão as menores porcentagens de idosos alfabetizados.

Portanto, para saber se as políticas públicas de saúde destinadas aos idosos estão realmente atingindo seus objetivos, é imprescindível que essa resposta venha por meio destes. Não se pode admitir que o baixo grau de instrução de idosos seja uma barreira para que seus direitos sejam garantidos. Para isso é que os profissionais de saúde devem ser bem instruídos e capacitados, para levar informação e conhecimento, principalmente, a essa parcela da população que na maioria das vezes têm seus direitos violados.

\section{Considerações Finais}

O envelhecimento populacional é um fenômeno mundial e no Brasil ocorre a passos largos, a população idosa é a que mais cresce atualmente no país e essa é uma constatação que exige mudanças, a começar pela inserção do idoso nesse novo panorama que se configura no cenário brasileiro, levando em consideração a sua percepção, que afinal de contas é a mais importante e fidedigna para que se conheça de fato como ocorre e quais as principais modificações geradas pela velhice.

É possível observar que mesmo com um aumento significativo no tocante a estudos sobre o envelhecimento ainda há uma escassez de pesquisas voltadas para a percepção dos idosos, como eles reagem e de que forma vivenciam esse processo, estudou-se a opinião do mundo acerca do idoso, porém é raro encontrar literaturas que se refiram à opinião do idoso a respeito do mundo. 
Por isso esse estudo buscou conhecer essas vertentes e verificou-se que a maioria dos idosos percebe de forma positiva o seu próprio processo de envelhecimento e o fato de terem alcançado uma nova fase em suas vidas, como é vista a terceira idade, é para eles um privilégio, principalmente por se encontrarem ativos e com saúde.

Notou-se que apesar da maioria encarar de forma positiva a velhice, não enxergam da mesma maneira as modificações que ocorrem através desta, demonstrando resignação como se o fato de serem velhos compreendesse apenas limitação e finitude.

Quando indagados sobre os sentimentos que tinham em relação a velhice, houve uma certa ambiguidade nas respostas, isso se deve ao fato de que sentimentos estão muito ligados a experiências pregressas e isso é muito peculiar a cada um, mas de modo geral não percebeu-se frustração nem dramaticidade durante as entrevistas.

Já quando questionados sobre as políticas públicas de saúde destinadas às pessoas idosas a grande maioria disse não conhecer a respeito, essa realidade pode está atrelada ao fato de que a maior parte tem um baixo nível educacional e isso pode ser determinante na compreensão do assunto, também demonstra uma falha dos profissionais da atenção básica no que concerne a promoção da saúde, orientar os idosos sobre os seus direitos e garantias é promover melhorias na qualidade de vida.

No que diz respeito à participação da família no processo de envelhecimento todos foram unânimes ao afirmar que é muito importante esse convívio atribuindo a ela sentimentos como união, segurança e amor. Para eles o contato com filhos, netos é um alicerce que os sustenta diante das dificuldades e torna mais leve as modificações causadas pela velhice.

Dessa forma, é necessário que haja mais estudos voltados para essa vertente do envelhecimento para que possamos compreender esse processo em todas as suas faces. A velhice não deve ser vista somente como um fator de riscos para doenças, pelo contrário, deve-se criar meios de integração social para o idoso, inseri-lo na sociedade como um ser atuante passível de ações, isso sem dúvidas também é promover saúde e cidadania.

Espera-se que esse estudo forneça dados relevantes sobre o assunto e que possa mobilizar autoridades, acadêmicos e profissionais da área para um novo olhar sobre a saúde do idoso, mais voltado para a promoção, proteção e livre de preconceito e discriminação.

\section{Referências}

ALVARENGA, L. N.; KYAN, L.; BITENCOURT, B.; WANDERLEY, K. S. Repercussão da Aposentadoria na Qualidade de Vida do Idoso. Rev. Esc. Enferm. São Paulo, v.43, n.4, pp.796-802, 2008. 
ARAúJO, L. F.; CARVAlHO, V. A. M. L. Aspectos Sócio-Históricos e Psicológicos da Velhice. Revista de Humanidades. Rio Grande do Norte, v.06, n.13, dez./jan. 2005.

ARANTES, R. C.; CORRÊA, C. S.; CAMARGOS, M. C. S.; MACHADO, C. J. Arranjos Domiciliares e Saúde dos Idosos: um estudo piloto qualitativo em um município do interior de Minas Gerais. Texto para Discussão n⿳005. Belo Horizonte, 2010.

AREOSA, S. V. C.; BENITEZ, L. B.; WICHMANN, F. M. A. Relações Familiares e o Convívio Social entre Idosos. Textos e Contextos. Porto Alegre, v.11, n.1, pp.184-192, jan./jul. 2012.

BALDIN, C. B.; FORTES, V. L. F. Viuvez Feminina: a fala de um grupo de idosas. RBCEH. Passo Fundo, v.5, n.1, pp.43-54, jan./jun. 2008.

BARDIN, L. Análise de Conteúdo. Lisboa: Edições 70, 2002.

BRITO, T. A.; FERNANDES, M. H.; COQUEIRO, R. S.; JESUS, C. S. Quedas e Capacidade Funcional em Idosos Longevos Residentes em Comunidade. Texto Contexto Enferm. Florianópolis, v.22, n.1, pp.43-51, jan./mar. 2013.

BRASIL. Ministério da Saúde. Resolução CNS 466/12. Diretrizes e Normas Regulamentadoras de Pesquisas Envolvendo Seres Humanos. Brasília: 2012.

. Ministério da Saúde. Caderno de Atenção Básica: Envelhecimento e Saúde da Pessoa Idosa. Série A. Normas e Manuais Técnicos Cadernos de Atenção Primária, n.19. Brasília: Ministério da Saúde, 2006.

. Ministério da Saúde. Secretaria de Atenção à Saúde. Departamento de Atenção Básica. Política Nacional de Atenção Básica. Brasília, 2012.

CAMACHO, A. C. L. F.; COELHO, M. J. Políticas públicas para a saúde do idoso: revisão sistemática. Rev. Bras. Enferm. Brasília, v.63, n.2, pp.279-84, mar./abr. 2010.

CAMARANO, A. A.; PASINATO, M. T. O envelhecimento populacional na agenda das políticas públicas. Instituto de Pesquisa Econômica Aplicada- IPEA, pp.253-292, 2004. 
CAMARANO, A. A.; KANSO, S. As Instituições de Longa Permanência para Idosos no Brasil. R. Bras. Est. Pop. Rio de Janeiro, v.27, n.1, pp.233-235, jan./jun. 2010.

CANIZARES, J. C. L.; JACOB FILHO, W. J. Fatores de Risco à Senilidade na Transição à Aposentadoria. Rev. Bras. Geriatr. Gerontol. Rio de Janeiro, v.14, n.3, pp.425-432, 2011.

CARREIRA, L.; RODRIGUES, R. A. P. Dificuldades dos familiares de idosos portadores de doenças crônicas no acesso à unidade básica de saúde. Rev. Bras. Enferm. Brasília, v.63, n.6, pp.939-9, nov./dez. 2010.

CAVAlli, L. F.; FREIBERGER, C.; KRAUSE, K. M. O.; NUNES, M. Principais alterações fisiológicas que acontecem nos idosos: uma revisão bibliográfica. XVI Seminário Interinstitucional de Ensino, Pesquisa e Extensão. 2011.

CIOSAK, S.I.; BRAZ, E.; COSTA, M. F. B. N. A.; NAKANO, N. G. R.; RODRIGUES, J; ALENCAR, R. A.; ROCHA, A. C. A. L. Senescência e Senilidade: novo paradigma na atenção básica de saúde. Rev. Esc. Enferm. São Paulo, v.45, n.2, pp.1763-8, 2011.

COUTRIM, R. M. E. Idosos Trabalhadores: perdas e ganhos nas relações intergeracionais. Sociedade e Estado. Brasília, v.21, n.2, pp.367-390, mai./ago, 2006.

FARINASSO, A. L. C. Perfil dos idosos em uma área de abrangência da estratégia de saúde da família. Dissertação (Mestrado em Enfermagem Fundamental) - Universidade de São Paulo, Escola de Enfermagem de Ribeirão Preto. São Paulo, 2005.

FERNANDES, M. G. M.; FRAGOSO, K. M. Atendimento domiciliário ao idoso na atenção primária à saúde. Revista APS. v.8, n.2, pp.173-180, jul./dez. 2005.

FERNANDES, M. G. M.; SOUTO, M. C.; COSTA, S. F. G.; FERNANDES, B. M. Qualificadores sócios demográficos, condições de saúde e utilização de serviços por idosos atendidos na atenção primária. Revista Brasileira de Ciências da Saúde. v.13, n.2, pp.13-20, 2009.

FERNANDES, M. T. O.; SOARES, S. M. O desenvolvimento de políticas públicas de atenção ao idoso no Brasil. Rev. Esc. Enferm. São Paulo, v.46, n.6, pp.1494-1502, 2012. 
FLORIANO, L. A.; AZEVEDO, R. C. S.; REINERS, A. A. O.; SUDRE, M. R. S. Cuidado Realizado pelo Cuidador Familiar ao Idoso Dependente, em Domicílio, no Contexto da Estratégia de Saúde da Família. Texto Contexto Enferm. Florianópolis, v.21, n.3, pp.543-8, jul./set. 2012.

FERNANDES, P. M. O Idoso e a Assistência Familiar: Uma Abordagem da Família Cuidadora Economicamente Dependente do Idoso. Rev Novo Enfoque. v.07, n.07,2008.

FECHINI, B. R. A.; TROMPIERI, N. O Processo de Envelhecimento: As principais Alterações que Acontecem com o Idoso com o Passar dos Anos. Revista Científica Internacional. v.01, n.7, jan./mar.2012.

FIGUEIREDO, M. L. F.; TYRREL, M. A. R.; CARVALHO, C. M. R. G.; LUZ, M. H. B. A.; AMORIM, F. C. M.; LOIOLA, N. L. A. As Diferenças de Gênero na Velhice. Rev. Bras. Enferm. Brasília, v.60, n.4, pp.422-7, jul./ago, 2007.

GIL, A. C. Como elaborar projetos de pesquisa. $4^{\circ}$ ed. São Paulo. Atlas. 2002.

GOMES, M. M. F.; TURRA, C. M.; FÍGOLI, M. G. B.; DUARTE, Y. A. O.; LEBRÃO, M. L. Associação entre Mortalidade e Estado Marital: uma análise para idosos residentes no Município de São Paulo, Brasil, Estudo SABE, 2000 e 2006. Cad. Saúde Pública. Rio de Janeiro, v.29, n.3, pp.566578, mar, 2013.

GONÇALVES, L. H. T.; ALVAREZ, A. M.; SENA, E. L. S.; SANTANA, L. W. S.; VICENTE, F. R. Perfil da família cuidadora de idoso doente/fragilizado do contexto sociocultural de Florianópolis, SC. Texto Contexto Enferm. Florianópolis, v.15, n.4, pp.570-7, out./dez. 2006.

GUERRA, A. C. L. C.; CALDAS, C. P. Dificuldades e Recompensas no Processo de Envelhecimento: a percepção do sujeito idoso. Ciência \& Saúde Coletiva. Rio de Janeiro, v.15, n.6, pp.2931-2940, 2010.

IBGE. Instituto Brasileiro de Geografia e Estatística. 2010. Disponível em: http://www.ibge.gov.br/home/estatistica/populacao/censo2010/indicadores_sociais_municipais/indica dores_sociais_municipais.pdfAcesso em: 31 julho.13. 
JEDE, M.; SPULDARO, M. Cuidado do Idoso Dependente no Contexto Familiar: Uma Revisão de Literatura. RBCEH. Passo Fundo, v.6, n.3, pp.413-421, set./dez, 2009.

JARDIM, V. C. F. S.; MEDEIROS, B. F.; BRITO, A. M. Um Olhar sobre o Processo de Envelhecimento: a percepção de idosos sobre a velhice. Rev. Bras. Geriatr. Gerontol. Rio de Janeiro, v.9, n.2, 2006.

KUCHEMANN, B. A. Envelhecimento populacional, cuidado e cidadania: velhos dilemas e novos desafios. Revista Sociedade e Estado. v.27, n.1, jan./abr. 2012.

LAKATOS, E.M.; MARCONI, M.A. Fundamentos de metodologia científica. $6^{\circ}$ ed. São Paulo: Atlas, 2006.

LIMA, A. P.; DELGADO, E. I. A Melhor Idade no Brasil: Aspectos Biopsicossociais Decorrentes do Processo de Envelhecimento. Revista de Educação Física. Ji-Paraná, v.1, n.2, pp.76-91, set./out. 2010.

LIMA, C. A.; TOCANTINS, F. R. Necessidades de saúde do idoso: perspectivas para a enfermagem. Rev. Bras. Enferm. Brasília, v.62, n.3, pp.367-73, mai./jun. 2009.

LIMA, C. K. G.; MURAI, M. C. Percepção do Idoso sobre o Próprio Processo de Envelhecimento. Rev. Enferm. v.6, pp. 15-22, 2005.

LUZ, M. M. C.; AMATUZZI, M. M. Vivências de Felicidade de Pessoas Idosas. Estudos de Psicologia. Campinas, v.25, n.2, pp.303-307, abr./jun, 2008.

MEIRELES, A. E.; PEREIRA, L. M. S.; OLIVEIRA, T. G.; CHRISTOFOLRTTI, G.; FONSECA, A. L. Alterações Neurológicas Fisiológicas ao Envelhecimento Afetam o Sistema Mantenedor do Equilíbrio. Rev. Neuro.Cienc. v.18, n.1, pp.103-108, 2010.

MENDES, M. R. S. S. B.; GUSMÃO, J.L.; FARO, A. C. M.; LEITE, R. C. B. O. A Situação Social do Idoso no Brasil. Acta Paul Enferm. v.18, n.4, pp.422-6, 2005. 
MINAYO, M.C. de et al (org.). Ciência, técnica e arte: desafio da pesquisa social. 21 ed. Petrópolis, RJ: Vozes, 2002.

MARTINS, M. S.; MASSAROLLO, M. C. K. B. Conhecimento de Idosos sobre seus Direitos. Acta Paul Enferm. São Paulo, v.23, n.4, pp.479-85, 2010.

MOTA, F. R. N.; OLIVEIRA, E. T.; MARQUES, M. B.; BESSA, M. E. P.; LEITE, B. M. B.; SILVA, M. J. Família e redes sociais de apoio para o atendimento dasdemandas de saúde do idoso. Esc Anna Nery. v.14, n.4, pp.833-838, out./dez. 2010..

MOTTA, L. B.; AGUiAR, A. C.; CALDAS, C. D. Estratégia Saúde da Família e a Atenção ao Idoso: experiências em três municípios brasileiros. Cad. Saúde Pública. Rio de Janeiro, v.27, n.4, pp.779786, abr, 2011.

MAFRA, S. C. T.; SILVA, E. P.; FONSECA, E. S.; ALMEIDA, A. V.; FREITAS, N. C. O envelhecimento nas diferentes regiões do Brasil: uma discussão a partir do censo demográfico 2010. In: SIMPÓSIO DO PROGRAMA DE EDUCAÇÃO TUTORIAL EM ECONOMIA DOMÉSTICA. 2013, Viçosa, Anais 2175-0718.

NUNES, D. P.; NAKATANI, A. Y. K.; SILVEIRA, E. A.; BACHION, M. M.; SOUZA, M. R. Capacidade funcional, condições socioeconômicas e de saúde de idosos atendidos por equipes de Saúde da Família de Goiânia (GO, Brasil). Ciência e Saúde Coletiva.v.15, n.6, pp.2887-2898, 2010.

OLIVEIRA, C. R. M.; SOUZA, C. S.; FREITAS, T. M.; RIBEIRO, C. Idosos e Família: Asilo ou Casa. Rio de Janeiro, 2006. Disponível em: http://www.psicologia.pt/artigos/textos/A0281.pdf Acesso em: 30 julho. 13.

PASCHOAL, S. M. P. Qualidade de vida do idoso: elaboração de um instrumento que privilegia sua opinião. Dissertação (Mestrado em Medicina) - Universidade de São Paulo. São Paulo, 2000.

PEREIRA, R. J.; COTTA, R. M. M.; FRANCESCHINI, S. C. C.; PRIORE, S. E. Características da saúde do idoso brasileiro. Rev Med. Minas Gerais, v.19, n.1, pp.44-50, 2009. 
PIMENTA, G. M. F.; COSTA, M. A. S. M. C.; GONÇALVES, L. H. T.; ALVAREZ, A. M. Perfil do familiar cuidador de idoso fragilizado em convívio doméstico da grande Região do Porto, Portugal. Rev. Esc. Enferm. v. 43, n.3, pp.604-14, 2009.

PINHEIRO, G. M. L.; ALVAREZ, A. M.; PIRES, D. E. P. A Configuração do Trabalho da Enfermeira na Atenção ao Idoso na Estratégia de Saúde da Família. Ciências e Saúde Coletiva. V.17, n.8, pp.2105-2015, 2012.

PNUD. Programa das Nações Unidas para o Desenvolvimento Online. Expectativa de vida do brasileiro cresce $\mathbf{1 4 \%}$ em 20 anos. Brasília, 30 jul. 2013. Disponível em: http://www.pnud.org.br/IDH/Atlas2013.aspx?indiceAccordion=1\&li=li_Atlas2013 Acesso em: 18 jul. 13.

PROTTI, S. T. A saúde do idoso sob a ótica da equipe do programa de saúde da família. Mestrado (Enfermagem em Saúde Pública) - Universidade de São Paulo, Departamento Enfermagem Materno Infantil e Saúde Pública. Ribeirão Preto, 2002.

PRADO, T. M. B.Participação: um estudo sobre idosos. 2006. 228f. Dissertação (Mestrado em Política Social) - Universidade Federal do Espírito Santo, Vitória, 2006.

PERES, M. A. C. A. Educação de Jovens e Adultos e o Analfabetismo na Velhice: Os idosos e a Exclusão Educacional. Revista HISTEDBR On-line. Campinas, n.38, pp.225-236, jun. 2010.

PORTO, I. O Idoso de Classe Média. Momento. Rio Grande, v.17, pp.67-94, 2004/2005.

PEDRAZZI, E. C.; MOTTA, T. T. D.; VENDRÚSCOLO, T. R. P.; WEHBE, S. C. C. F.; CRUZ, I. R.; RODRIGUES, R. A. P. Arranjo Domiciliar dos Idosos mais Velhos. Rev. Latino-Am. Enfermagem. Ribeirão Preto, v.18, n.1, jan./fev, 2010.

RIBEIRO, A. P.; PIRES, V. A. T. N. Atuação do enfermeiro da estratégia saúde da família na atenção à saúde do idoso. Revista Enfermagem Integrada. Ipatinga, v.4, n.2, nov./dez. 2011.

RIBEIRO, L. C. C.; ALVES, P. B.; MEIRA, E. P. Percepção dos Idosos sobre as Alterações Fisiológicas do Envelhecimento. Cienc. Cuid. Saúde. v.8, n.2, pp.220-227, abr./jun, 2009. 
RISSARDO, L. K.; FURLAN, M. C. R.; GRANDIZOLLI, G.; MARCON, S. S.; CARREIRA, L. Concepção e Sentimentos de Idosos Institucionalizados sobre Família. Cienc. Cuid. Saude. v.10, n.4, pp.682-689, 2011.

ROACH, S. Introdução à Enfermagem Gerontológica. Rio de Janeiro. Guanabara Koogan, 2003.

SALGUEIRO, H.; LOPES, M. A dinâmica da família que coabita e cuida de um idoso dependente. Rev Gaúcha Enferm. Porto Alegre, v.31, n.1, pp.26-32, mar. 2010.

SANTOS, A. A.; PAVARINI, S. C. I.; BARHAM, E. J. Percepção de Idosos Pobres com Alterações Cognitivas sobre funcionalidade familiar. Texto Contexto Enferm. Florianópolis, v.20, n.1, pp.10210, jan./mar.2011.

SANTOS, S. S. C.; BARLEM, E. L. D.; SILVA, B. T.; CESTARI, M. E.; LUNARDI, V. L. Promoção da saúde da pessoa idosa: compromisso da enfermagem gerontogeriátrica. Acta Paul Enferm. v.21, n.4, pp.649-53, 2008.

SANTOS, A. F. A.Qualidade de vida e solidão na terceira idade. 2008. Trabalho de Conclusão de Curso (Graduação em Psicologia) - Curso de Psicologia, Universidade Fernando Pessoa, Porto, 2008.

SILVA, L. C. C.; FARIAS, L. M. B.; OLIVEIRA, T. S.; RABELO, O. F. Atitude de Idosos em Relação à Velhice e Bem Estar Psicológico. Revista Kairós Gerontologia. São Paulo, v.15, n.3, pp.119-140, 2012.

SCHIMIDT, T. C. G.; SILVA, M. J. P. Percepção e compreensão de profissionais e graduandos de saúde sobre o idoso e o envelhecimento humano. Rev. Esc. Enferm. v.46, n.3, pp.612-7, 2011.

SCHNEIDER, R. H.; IRIGARAY, T. Q. O Envelhecimento na Atualidade: aspectos cronológicos, biológicos, psicológicos e sociais. Estudos de Psicologia. Campinas, v.25, n.4, pp.585-593, out./dez, 2008.

SCORTEGAGNA, P. A.; OLIVEIRA, R. C. S. Idoso: um novo ator social. ANPEDSUL. Seminário de Pesquisa em Educação da Região Sul, 2012. 
SCOSS, D. M. Os benefícios do treinamento de força sobre alterações dos sistemas fisiológicos associados à saúde na terceira idade. Revista Conaef. v.1,n.1, 2012.

SILVA, C. A.; FOSSATTI, A. F.; PORTELLA, M. R. Percepção do homem idoso em relação às transformações decorrentes do processo do envelhecimento humano. Estud. Interdiscip. Envelhec. Porto Alegre, v.12, pp.111-126, 2007.

SILVESTRE, J. A.; COSTA NETO, M. M. Abordagem do idoso em programas de saúde da família. Cad. Saúde Pública. Rio de Janeiro, v.19, n.3, pp.839-847, mai./jun. 2003.

SIMSON, O. R. M. V.; NERI, A. L.; CACHIONI, M. As Múltiplas Faces da Velhice no Brasil.2º ed. São Paulo. Alínea, 2006.

SMELTZER, S. C.; BARE, B. G.; HINKLE, J. L.; CHEEVER, K. H. Tratado de Enfermagem Médico-Cirúrgica. $11^{\circ}$ ed. Rio de Janeiro: Guanabara Koogan, 2009.

SILVA, A. C.Estatuto do idoso: análise do conhecimento dos idosos atendidos pela estratégia saúde da família. 2013. 145f. Dissertação (Mestrado em Gerontologia Biomédica)- Universidade Católica do Rio Grande do Sul, Porto Alegre, 2013.

SOUZA, R. F.; SKUBS, T.; BRÊTAS, A. C. P. Envelhecimento e família: uma nova perspectiva para o cuidado de enfermagem. Rev. Bras. Enferm. Brasília, v.60, n.3, pp.263-7, mai./jun.2007.

TAVARES, V. O.; TEIXEIRA, K. M. D.; WAINMAN, S.; LORETO, M. D. S. Interfaces entre a Renda dos Idosos Aposentados Rurais e o Contexto Familiar. Textos \& Contextos. Porto Alegre, v.10, n.1, pp.94-108, jan./jul. 2011.

TAHAN, J.; CARVALHO, A. C. D. Reflexões de idosos participantes de grupos de promoção de saúde acerca do envelhecimento e da qualidade de vida. Saúde Soc. São Paulo, v.19, n.4, pp.878-888, 2010.

TORRES, M. M.; SÁ, M. A. A. S. Inclusão Social de Idosos: um longo caminho a percorrer. Revista Ciências Humanas. v. 1, n.2, 2008. 
VERAS, R. Envelhecimento populacional contemporâneo: demandas, desafios e inovações. Rev Saúde Pública. v.43, n.3, pp.548-54, 2009.

VILElA, A. B. A.; CARVAlHO, P. A. L.; ARAÚJO, R. T. Envelhecimento Bem-Sucedido: representação de idosos. Rev. Saúde. Com. Bahia, v.2, n.2, pp.101-114, 2006.

WONG, L. L. R.; CARVALHO, J. A. O rápido processo de envelhecimento populacional do Brasil: sérios desafios para as políticas públicas. R. Bras. Est. Pop. São Paulo, v.23, n.1, pp.5-26, jan./jun. 2006.

YAMAMOTO, C. M. K. Promoção da saúde do idoso: revisão de literatura brasileira.Dissertação (Mestrado em Saúde Pública) - Universidade de São Paulo, Faculdade de Saúde Pública. São Paulo, 2010.

\section{Como citar este artigo (Formato ISO):}

OLIVEIRA, N.S.; SOUZA, T.S.; ALENCAR, F.S.; OLIVEIRA, G.L.; FERREIRA, N.B.; ALENCAR, J.S. Percepção dos idosos sobre o processo de envelhecimento. Id on Line Revista de Psicologia, Fevereiro de 2014, vol.8, n.22, p. 49-83. ISSN 1981-1189. 